\title{
A RELAÇÃO ENTRE OS RANKINGS FORMADOS PELOS INDICADORES SOCIOAMBIENTAIS E OS ECONÔMICO-FINANCEIROS DAS EMPRESAS DISTRIBUIDORAS DE ENERGIA ELÉTRICA
}

\author{
THE RELATIONSHIP BETWEEN THE RANKINGS FORMED BY THE ENVIRONMENTAL \\ AND ECONOMIC-FINANCIAL INDICATORS OF ELECTRICITY DISTRIBUTION \\ COMPANIES
}

\author{
Itzhak David Simão Kaveski \\ itzhak.konoha@gmail.com
}

Universidade Federal do Mato Grosso do Sul
José Augusto Sousa Martins

martins_cont@hotmail.com

Universidade Regional de Blumenau

\author{
Nelson Hein \\ hein@furb.br \\ Universidade Regional de Blumenau
}

\section{RESUMO}

O objetivo deste estudo é avaliar o grau de relacionamento entre os rankings formados pelos indicadores econômico-financeiros e socioambientais das empresas distribuidoras de energia elétrica, filiadas ao Operador Nacional do Sistema Elétrico (ONS). A população e a amostra deste estudo é composta por empresas do setor de distribuidoras de energia elétrica, filiadas ao Operador Nacional do Sistema Elétrico (ONS), no período de 2011. Para análise dos dados utilizou-se o método multicritério para tomada de decisão VIKOR e correlação de Kendall. Os resultados desta pesquisa indicam que as empresas ocupam posições semelhantes nos rankings econômico-financeiros e socioambientais. A correlação de Kendall demonstrou uma relação positivamente significante entre os rankings, apoiando a ideia de que empresas distribuidores de energia elétrica com altos desempenhos econômico-financeiros, possuem maiores responsabilidades socioambientais.

Palavras-chave: Indicadores econômico-financeiros, Responsabilidade socioambiental, Rankings.

\section{ABSTRACT}

The objective of this study is to assess the degree of relationship between the rankings formed by financial indicators and socioenvironmental of companies electricity distribution companies, affiliated to the National System Operator Electricity (ONS). The population and study sample consists of companies in the electricity distributors, affiliated to the National System Operator Electricity (ONS) during 2011. Data analysis used the method for multicriteria decision making VIKOR and Kendall correlation. The results of this research indicate that companies occupy similar positions in the rankings economic, financial and environmental. The Kendall correlation showed a significant positive relationship between the rankings, supporting the idea that firms electricity distributors with high economic and financial performance, have higher socioenvironmental responsibilities.

Keywords: Economic and Financial Indicators, Socioenvironmental responsibility, Rankings.

Artigo recebido em: 25.11.2013; Aceito em: 15.02.2014 


\section{Introdução}

Nas últimas décadas emergiram discussões sobre o tema responsabilidade socioambiental, tanto no ambiente acadêmico como nos negócios. As organizações além de se preocuparem com o desempenho econômico-financeiro começaram a buscar a melhoria da qualidade socioambiental na região onde desenvolvem suas atividades. A preocupação das empresas com a responsabilidade socioambiental se reveste de uma postura mais ética das organizações, deixando de se preocupar apenas com os lucros, mas também com a realidade social, cultural e ambiental. Contudo, as organizações necessitam de um equilíbrio entre os benefícios originados pelas atividades econômico-financeiras e os investimentos socioambientais, de modo que estes investimentos realizados não comprometam a continuidade da organização (CALIXTO, 2008; MACHADO; MACHADO 2009; CERETTA et al. 2009; HOLANDA et al. 2011).

As primeiras discussões sobre os investimentos sociais realizado pelas entidades iniciaram-se com a teoria dos stakeholders a qual é defendida pelos pesquisadores Levitt (1958) e Friedman (1988). Segundo os autores as organizações devem se preocupar com a maximização dos lucros para seus acionistas, assim a responsabilidade social passa a ser uma função do Estado. Entretanto, Carrol (1979) e Freeman (1984) defendem que a responsabilidade das empresas está além da maximização dos lucros, devendo esta também se preocupar com a promoção do bemestar social. Por fim, Elkingto (1998) avalia a empresa sob três aspectos, denominado de triple botton line, o econômico, ambiental e social. Conforme o autor, para que as empresas sejam bem sucedidas em suas atividades devem apresentar sucesso além do aspecto econômico (lucro), no ambiental e social.

De acordo com Calixto (2010, p. 124) "o desenvolvimento sustentável tem sido a principal justificativa para que as instâncias públicas e privadas promovam o bem-estar social e permitam a continuidade e manutenção dos recursos naturais para as próximas gerações”. Segundo o autor, o impacto gerado pela instalação das hidrelétricas das empresas do setor de energia elétrica elevou o comprometimento por parte das companhias com questões sociais e ambientais, incentivando a divulgação seus balanços sociais desde 2002.

Neste sentido apresenta-se a questão problema: Qual o grau de relacionamento entre os rankings formados pelos indicadores econômico-financeiros e socioambientais das empresas distribuidoras de energia elétrica filiadas ao Operador Nacional do Sistema Elétrico (ONS)? O objetivo do estudo é analisar a relação dos rankings formados pelos indicadores econômicofinanceiros e socioambientais das empresas distribuidoras de energia elétrica filiadas ao Operador Nacional do Sistema Elétrico (ONS).

Este estudo se justifica pelas características das empresas do setor de energia elétrica, as quais são potencialmente causadoras de grandes impactos ambientais, porém, por outro lado a energia elétrica é de fundamental importância para o desenvolvimento econômico e social. Desta forma, a busca pelo conhecimento da relação entre desempenho econômico-financeiro e investimento socioambiental torna-se atraente, visto que a pesquisa busca verificar empiricamente se o investimento realizado pelas organizações no ambiente socioambiental reflete positivamente em seu desempenho econômico-financeiro e assim, por consequência, atende aos interesses de seus stakeholders.

\section{Revisão da Literatura}

Este capítulo possui como objetivo apresentar argumentos teóricos que trazem sustentação para a presente pesquisa. Inicialmente é exposta a Teoria dos Stakeholders, a qual serve de base para o estudo. No segundo momento, explanou-se acerca sobre o tema responsabilidade 
socioambiental. Por fim, traz-se estudos anteriores que objetivaram em encontrar a relação entre os investimentos socioambientais com o desempenho empresarial.

\subsection{Teoria dos stakeholder}

A teoria dos stakeholders é a mais utilizada pela literatura para explicar a relação entre os investimentos socioambientais com a performance econômico-financeira, visto que esta teoria estabelece que os gestores tomam decisões através dos interesses de todos os stakeholder da organização (CERETTA et al. 2009). Conforme Freeman (1984) os stakeholders é qualquer grupo ou indivíduo que pode afetar ou é afetado pela realização dos objetivos da empresa. De tal modo, que os stakeholders são os investidores, clientes, o governo, empregados concorrentes, entre outros, além da sociedade e ambientalistas.

Conforme Donaldson e Preston (1995), a teoria dos stakeholders defende que as pessoas ou grupos de pessoas possuem interesses legítimos nos processos ou nos impactos das atividades da empresa, o que a diferencia de outras teorias que abordam o ambiente empresarial. Assim, conforme os autores a teoria dos stakeholders não parte apenas do pressuposto de um único foco legitimo de controle e governança corporativa, mas sim de aspectos diversos e alternativos, caracterizados em instrumental, descritivo e normativo.

As organizações devem avaliar seus stakeholders como aqueles considerados cruciais para as empresas, ou seja, sem os quais as entidades deixariam de existir (MITCHELL; AGLE; WOOD, 1997). De acordo com Mitchell, Agle e Wood (1997) os stakeholders devem ser classificados em diferentes grupos de interesses e funções como "poder", "legitimidade" e "urgência", com diferentes atributos. Conforme Freeman e McVea (2001), a teoria dos stakeholders vem se desenvolvendo dentro de quatro linhas distintas de pesquisa: o planejamento corporativo; a teoria de sistemas; a responsabilidade social corporativa; e a teoria organizacional. Destaca-se a responsabilidade social, o qual os autores salientam que nesta linha é indicado a importância da construção de um relacionamento forte e confiável entre as organizações e os grupos externos, buscando o sucesso da gestão empresarial.

Arantes (2006) salienta que de modo geral, a sociedade e o mercado como um todo tem cobrado uma postura socialmente responsável pelas organizações, minimizando a desigualdades sociais e os impactos negativos causados por algum setores da economia no desenvolvimento de suas atividades. Dessa forma, o objetivo das empresas deixam de ser apenas em caráter econômico, mas também em caráter socioambiental.

As mudanças ocorridas no comportamento dos stakeholders e do mercado promoveram uma alteração no foco das organizações, que anteriormente buscavam atender apenas seus shareholders, passam a atender também os stakeholders (FREEMAN; REED, 1983). Desta forma, a relação encontrada através do desempenho econômico-financeiro e socioambiental das organizações deve apresentar um resultado positivo, visto que, conforme a teoria dos stakeholders, os resultados encontrados através da relação, demonstrariam uma eficiência da administração no que tange a consecução dos objetivos organizacionais e atendimento das expectativas de seus stakeholders nos aspectos econômico, social e ambiental (BORBA, 2005).

\subsection{Responsabilidade socioambiental}

Os debates referentes à responsabilidade socioambiental, iniciou partir do reconhecimento das questões relacionadas ao papel social que as empresas possuem no contexto em que estão inseridas, visto que inicialmente era considerado como única responsabilidade das empresas o lucro (FRIEDMAN, 1970). Assim, o fato da responsabilidade empresarial vêm evoluindo ao longo do tempo, as empresas passam a identificar outros interesses envolvidos pelos processos 
econômico-financeiros, como a responsabilidade socioambiental, ganhando crescente relevância em vários setores da sociedade (FREEMAN, 1984).

Conforme o Instituto Ethos (2006), a responsabilidade socioambiental pode ser definida como pela relação entre a ética, transparente e solidária das empresas com o meio que ela se relaciona, estabelecendo metas empresariais compatíveis para o desenvolvimento socioambiental, auxiliando para a preservação dos recursos ambientais e cultuarias, promovendo a redução das desigualdades sociais. Segundo Elkington (1998) as empresas devem se guiar na direção da responsabilidade socioambiental, envolvendo-se em práticas sociais e ambientais, além de atender o caráter lucrativo a qual o mesmo está submetido.

Elkington (1998) propõe o Triple Bottom Line, enfatizando duas questões: a integração entre os aspectos económicos, social e ambiental, e a integração entre as visões de curto e longo prazo. Na primeira questão, é discutido que a sustentabilidade econômica como uma condição isolada dentro das organizações não é suficientemente significativa para uma sustentabilidade global. Sobre a segunda questão, o autor salienta que a ambição das empresas por lucros imediatos é completamente oposta a visão de uma empresa sustentável, que exige a satisfação das necessidades das gerações atuais, não comprometendo as necessidades de gerações futuras. Segundo Ferreira (2004, p. 137) o crescimento dos investimentos socioambientais "reforça a relação entre a responsabilidade social e a valorização dos papéis da empresa." De acordo com Rezende, Nunes e Portela (2008) o mercado acionário vêm buscado novas meios para investirem seus fundos os quais ocasionam uma maximização do retorno aos stakeholders e uma minimização do risco. Dentre os meios existentes para o investimento, destaca-se os socioambientais que surgiu com a necessidade que os stakeholders possuíam em encontrar novas alternativas para seus investimentos, aliando a empresa a um desenvolvimento sustentável, social e com práticas de governança corporativa.

Dentre as diversos instrumento de evidenciação da responsabilidade social e corporativa, destaca-se o Balanço Social. O Balanço Social é um meio que as empresas possuem para a transparência de suas atividades corporativas, apresentando três principais indicadores: indicadores sociais internos (ISI), evidenciando os investimentos feitos pela empresa internamente, sejam obrigatórios ou voluntários, buscando beneficiar e/ou atender ao corpo funcional da entidade; os indicadores sociais externos (ISE), que demonstram os investimentos voluntários realizado pelas organizações, cujo público-alvo é a sociedade em geral; e os indicadores ambientais (IA), apresentando os investimentos que as entidades fazem para suavizar ou compensar seus impactos ambientais, além de proporcionar uma melhora na qualidade ambiental (IBASE).

\subsection{Estudos anteriores}

Neste tópico é apresentado uma síntese de estudos relacionados à área de socioambiental que investigaram a relação entre os mesmos com as variáveis econômico-financeiras em diferentes setores empresariais. O Quadro 2 apresenta os estudos anteriores relacionados ao tema.

Quadro 1 - Estudos anteriores

\begin{tabular}{|c|c|c|}
\hline Autores & Objetivo & Resultados \\
\hline $\begin{array}{l}\text { Castro Júnior, Abreu e } \\
\text { Soares (2005) }\end{array}$ & $\begin{array}{l}\text { Analisar a relação entre o } \\
\text { comportamento ambiental e o } \\
\text { desempenho financeiro das empresas } \\
\text { de fiação e tecelagem listadas na } \\
\text { Bovespa. }\end{array}$ & $\begin{array}{l}\text { Os resultados indicam que existe uma } \\
\text { relação positiva entre as variáveis } \\
\text { econômico-financeiras (Retorno } \\
\text { sobre o Patrimônio Líquido, Ativo } \\
\text { Total, Lucro Líquido, Faturamento } \\
\text { Líquido e EBITDA) e a conduta } \\
\text { ambiental das empresas de fiação e } \\
\text { tecelagem. }\end{array}$ \\
\hline
\end{tabular}

R. Cont. Ufba, Salvador-Ba, v. 7, n. 3, p. 59 - 73, dezembro-março 2014 


\begin{tabular}{|c|c|c|}
\hline Borba (2005) & $\begin{array}{ll}\text { Analisar a } & \text { relação entre o } \\
\text { desempenho } & \text { socioambiental e } \\
\text { desempenho econômico-financeiro } \\
\text { das empresas brasileiras listadas na } \\
\text { Bovespa. }\end{array}$ & $\begin{array}{l}\text { Os achados demonstram que não há } \\
\text { relação estatisticamente positiva ou } \\
\text { negativa significante entre o } \\
\text { desempenho socioambiental e o } \\
\text { desempenho econômico-financeiro } \\
\text { (lucro operacional sobre ativo total, } \\
\text { lucro operacional próprio sobre ativo } \\
\text { total, retorno da geração bruta de } \\
\text { caixa sobre o ativo, } q \text { de Tobin e } \\
\text { valor da firma) corporativos das } \\
\text { empresas listadas na Bovespa. }\end{array}$ \\
\hline Arantes (2006) & $\begin{array}{l}\text { Verificar a relação entre o } \\
\text { investimento socioambiental e o } \\
\text { desempenho econômico-financeiro } \\
\text { das empresas com negociações } \\
\text { negociadas nas bolsas de valores de } \\
\text { Nova Iorque e São Paulo. }\end{array}$ & $\begin{array}{l}\text { Os resultados apontam que que } \\
\text { empresas que } \\
\text { desenvolver } \\
\text { responsáveis }\end{array}$ \\
\hline Tupy (2008) & $\begin{array}{l}\text { Analisar as relações entre variáveis } \\
\text { socioambientais e econômico- } \\
\text { financeiras, das empresas } \\
\text { pertencentes ao índice IBR-X } 50 \text { e no } \\
\text { Îndice de Sustentabilidade da } \\
\text { BM\&FBovespa. }\end{array}$ & $\begin{array}{l}\text { Os achados evidenciam que não } \\
\text { existem relações estatisticamente } \\
\text { significativas entre variáveis } \\
\text { econômico-financeiras r e } \\
\text { socioambientais, das empresas } \\
\text { pertencentes ao índice IBR-X } 50 \text { e do } \\
\text { ISE. }\end{array}$ \\
\hline Ceretta et al. (2009) & $\begin{array}{l}\text { Verificar se existe relação entre os } \\
\text { investimentos socioambientais e a } \\
\text { performance econômico-financeira } \\
\text { de empresas brasileiras. }\end{array}$ & $\begin{array}{l}\text { Os resultados indicam uma relação } \\
\text { significativa positiva entre os } \\
\text { indicadores sociais externos e a } \\
\text { receita líquida e entre indicadores } \\
\text { sociais internos, indicadores sociais } \\
\text { externos, indicadores defasados com } \\
\text { o resultado líquido }\end{array}$ \\
\hline Machado e Machado (2011) & $\begin{array}{l}\text { Verificar se as variáveis } \\
\text { socioambiental causam impacto no } \\
\text { desempenho econômico-financeiro } \\
\text { das } 500 \text { maiores e melhores } \\
\text { empresas, segundo a publicação } \\
\text { anual da Revista Exame no período } \\
\text { de } 2003 \text { a } 2007 \text {. }\end{array}$ & $\begin{array}{l}\text { Os achados evidenciam que existe } \\
\text { um impacto positivo das variáveis } \\
\text { socioambientais (ISE e ISI) no } \\
\text { desempenho econômico-financeiro } \\
\text { (receita líquida, resultado } \\
\text { operacional e Ebitda). Contudo, } \\
\text { dentre as variáveis socioambientais a } \\
\text { que representa os indicadores } \\
\text { ambientais não se encontrou um } \\
\text { impacto positivo ou negativo no } \\
\text { desempenho econômico-financeiro. }\end{array}$ \\
\hline $\begin{array}{l}\text { Souza, Parisotto e } \\
\text { Marcondes (2011) }\end{array}$ & $\begin{array}{l}\text { Verificar a relação entre a divulgação } \\
\text { do Balanço Social e o resultado } \\
\text { econômico-financeiro das empresas } \\
\text { do setor de eletricidade. }\end{array}$ & $\begin{array}{l}\text { Os resultados apontam que os } \\
\text { indicadores sociais externos e } \\
\text { internos receberam um maior volume } \\
\text { de investimento. Destaca-se que o } \\
\text { crescimento dos indicadores sociais } \\
\text { internos e externos foi acompanhado } \\
\text { pelas variáveis econômico- } \\
\text { financeiras (receita operacional } \\
\text { líquida, lucro líquido e Ebitida). }\end{array}$ \\
\hline Holanda et al. (2011) & $\begin{array}{l}\text { Investigar a associação entre } \text { o } \\
\text { desempenho socioambiental e o } \\
\text { desempenho econômico-financeiro, } \\
\text { das empresas do setor elétrico } \\
\text { brasileiro } \\
\text { BM\&FBovespa. listadas }\end{array}$ & $\begin{array}{l}\text { Os achados demonstram que não há } \\
\text { relação estatisticamente positiva ou } \\
\text { negativa significante entre a relação } \\
\text { do desempenho socioambiental com } \\
\text { desempenho econômico-financeiro, } \\
\text { das empresas do setor elétrico }\end{array}$ \\
\hline
\end{tabular}

R. Cont. Ufba, Salvador-Ba, v. 7, n. 3, p. 59 - 73, dezembro-março 2014 


\begin{tabular}{|l|l|lr|}
\hline & & $\begin{array}{l}\text { nasileiro listadas } \\
\text { BM\&FBovespa. }\end{array}$ \\
\hline \multirow{3}{*}{ Orellano e Quiota (2011) } & $\begin{array}{l}\text { Investiga a relação entre os os } \\
\text { investimentos socioambientais e o } \\
\text { desempenho econômico-financeiro, } \\
\text { de diversas empresas brasileiras no } \\
\text { período de 2001 a 2007. }\end{array}$ & $\begin{array}{l}\text { Os resultados revelam } \\
\text { correlação positiva } \\
\text { investimento socioambientais e } \\
\text { desempenho econômico-financeiro, } \\
\text { sobretudo o investimento social } \\
\text { interno. }\end{array}$ \\
\hline
\end{tabular}

Fonte: Elaborado pelos autores.

Pode-se verificar no Quadro 2 que em diversos trabalhos foram encontrados relações positivas entre as variáveis socioambientais e as variáveis econômico-financeiras. Assim, esse estudo busca analisar a relação dos rankings formados pelos indicadores econômico-financeiros e socioambientais, das empresas distribuidoras de energia elétrica, filiadas ao Operador Nacional do Sistema Elétrico (ONS).

\section{Procedimentos Metodológicos}

O presente estudo caracteriza-se como uma pesquisa descritiva, documental e de abordagem quantitativa. De acordo com Vergara (2006, p. 47) "a pesquisa descritiva expõe características de determinada população ou de determinado fenômeno". Configura-se como pesquisa documental, conforme Marconi e Lakatos (2010) por utilizar-se dos relatórios de socioambientais e financeiros publicados pelas empresas distribuidoras de energia elétrica, associadas ao Operador Nacional do Sistema Elétrico (ONS) no ano de 2011 como fonte dos dados para a pesquisa. A abordagem é quantitativa devido ao uso de instrumentos estatísticos nas fases de coleta, tratamento e análise dos dados, conforme preconizado por Richardson (1999).

Foram examinados os relatórios de socioambientais e financeiro referente aos exercícios sociais das empresas distribuidoras de energia elétrica associadas ao Operador Nacional do Sistema Elétrico (ONS). O universo totaliza em 39 empresas, para a amostra da pesquisa, realizou um cruzamento de dados para formar uma amostra de 32 empresas, isso ocorreu, uma vez que, ocorreu de empresas não demonstraram os relatórios socioambientais de 2011.

Os dados utilizados para a análise estatística foram retirados das demonstrações socioambientais e financeiras das empresas compostas na amostra. Foram considerados os mesmos dados utilizados por diversos estudos que buscaram observar a relação entre as variáveis econômico-financeiras e socioambientais. As varáveis são apresentadas no Quadro 2.

Quadro 2 - Variáveis da pesquisa

\begin{tabular}{|c|c|c|}
\hline Dados & Variável & Identificação \\
\hline \multirow{4}{*}{ Índice Econômico-financeiros } & REN\% & Rentabilidade do Patrimônio Líquido em \%. \\
\cline { 2 - 3 } & LL & Lucro Líquido do exercício em R\$ milhões. \\
\cline { 2 - 3 } & GC & $\begin{array}{c}\text { Geração de Caixa do exercício, representada pelo valor do } \\
\text { LAJIDA ou EBITDA em R\$ milhões. }\end{array}$ \\
\hline \multirow{3}{*}{ Índice Socioambiental } & RL & $\begin{array}{c}\text { Resultado Operacional Líquido do exercício em R\$ } \\
\text { milhões. }\end{array}$ \\
\cline { 2 - 3 } & ISI & Indicadores Sociais Internos do exercício em R\$ milhões. \\
\cline { 2 - 3 } & ISE & Indicadores Sociais Externos do exercício em R\$ milhões \\
\hline
\end{tabular}

Fonte: Dados da pesquisa.

Para obtenção dos dados necessários para determinação dos indicadores econômico-financeiros e socioambientais, utilizou-se às demonstrações disponibilizadas no endereço eletrônico das 
empresas. Os dados coletados referem-se ao ano de 2011, o qual foram estruturados em planilha pelo Microsoft Excel®. Na sequência, foram elaborados, por meio do método multicritério para tomada de decisão VIKOR, os rankings socioambientais e econômico-financeiros das empresas. Optou-se por fazer os rankings pelo método do VIKOR por ser desenvolvido para optimização multicritério de sistemas complexos, é uma ferramenta adequada para avaliar cada alternativa para cada função critério (OPRICOVIC; TZENG, 2004, 2007; TZENG; LIN; OPRICOVIC, 2005). Conforme Opricovic e Tzeng (2004) o VIKOR possui como foco avaliação e a classificação a partir de um conjunto de alternativas na presença de critérios contraditórios, apresentando uma classificação multicritério com base na medida especial de proximidade com a solução ideal.

As etapas principais do método VIKOR são descritos conforme os autores Opricovic e Tzeng (2004 e 2007) e Tzeng, Lin e Opricovic (2005), como se segue:

Passo 1: Determinar os melhores valores $f_{i}^{*} \mathrm{e}$ os piores valores $f_{i}^{-}$de toda a função, $i=1,2, \ldots, \mathrm{n}$.

$$
f_{i}^{*}=\max _{j} f_{i j} f_{i}^{-}=\min _{j} f_{i j}
$$

Passo 2: Calcular os valores $S_{j}$ (é o grupo de utilidade máxima) e $R_{j}$ (é o peso individual mínimo), $j=1,2, \ldots, J$, nas relações, em que $w_{i}$ são os pesos dos critérios.

$$
\begin{aligned}
S_{j} & =\frac{\sum_{i=1}^{n} w_{i}\left(f_{i}^{*}-f_{i j}\right)}{f_{i}^{*}-f_{i}^{-}}, \\
R_{j} & =\max _{j}\left[\frac{w_{i}\left(f_{i}^{*}-f_{i j}\right)}{f_{i}^{*}-f_{i}^{-}}\right],
\end{aligned}
$$

Figura 3 - Compromissos e soluções ideais

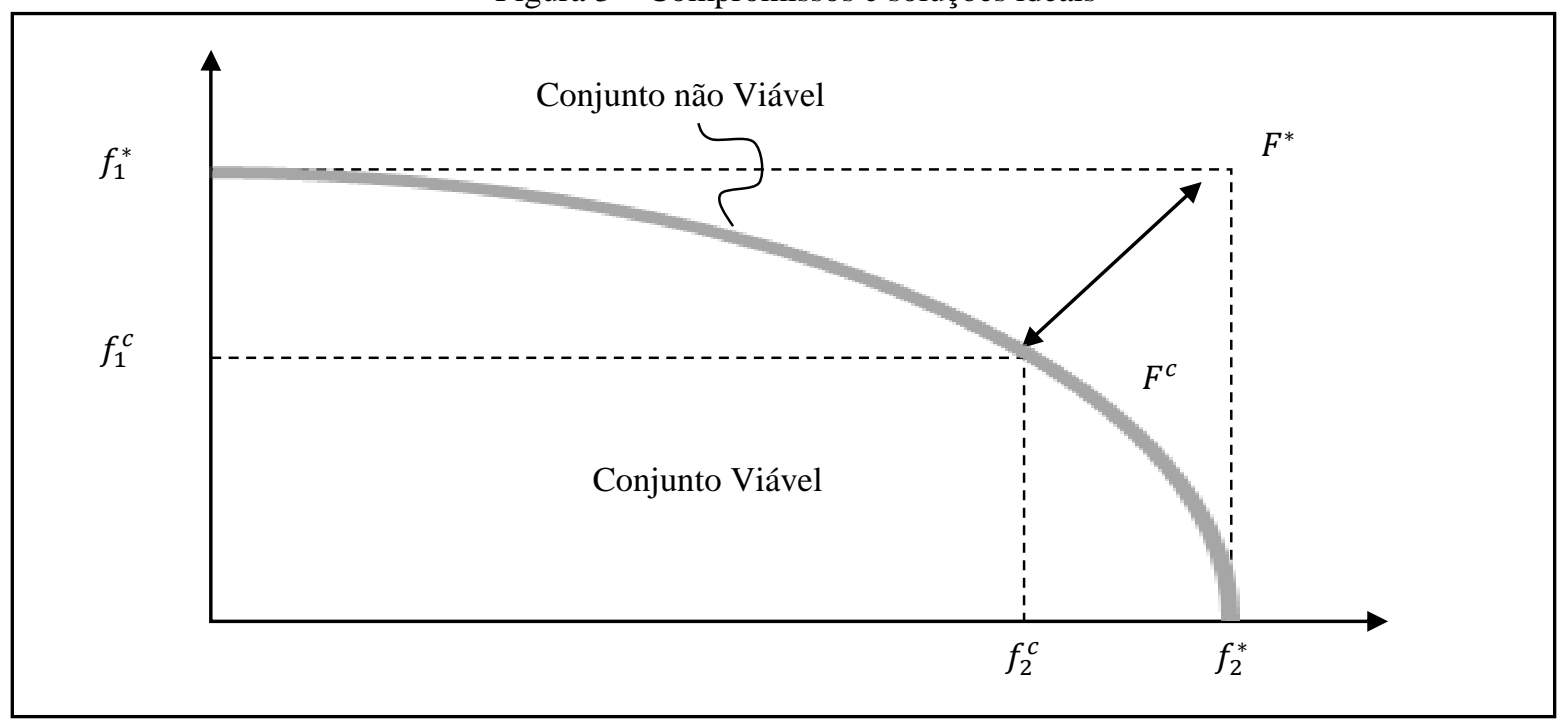

Fonte: Opricovic e Tzeng (2004). 
Passo 3: Calcular os valores $Q_{j}, j=1,2, \ldots, J$, pela relação, em que $S^{*}=\min _{j} S_{j}$, $S^{-}=\max _{j} S_{j}$ e $R^{*}=\min _{j} R_{j}, R^{-}=\max _{j} R_{j}$, o vé introduzido como peso de estratégia geralmente utilizado como $v=0,5$.

$$
Q_{j}=\frac{v\left(S_{j}-S^{*}\right)}{S^{-}-S^{*}}+\frac{(1-v)\left(R_{J}-R^{*}\right)}{R^{-}-R^{*}}
$$

Passo 4: Classificar as alternativas de forma decrescente, pelos valores obtidos por $\mathrm{S}, \mathrm{R}$ e Q. Os resultados são três listas de classificação, contudo pode se considerar apenas os valores obtidos por $\mathrm{Q}$.

Por fim, foi calculado o coeficiente de correlação de Kendall. O coeficiente de correlação de $\tau$ de Kendall é uma medida não-paramétrica do grau de correlação monótona, ou seja, linear ou não linear entre duas variáveis, X e Y. O coeficiente de Kendall depende apenas dos rankings formados pelos dados, não necessitando dos valores observados de cada variável. Como tal, o coeficiente de Kendall mede também a correlação não-linear existente entre duas variáveis, além de ser mais resistente aos efeitos das variáveis outliers (KENDALL, 1970).

Com o intuito de avaliar o relacionamento entre os rankings econômico-financeiros e socioambientais, foi utilizado o coeficiente de correlação de Kendall, pois é o mais utilizado para verificar a relação entre os rankings. Para cálculo deste coeficiente utilizou-se o software Statistical Package for the Social Sciences (SPSS).

\section{Descrição e Análise dos Resultados}

Na Tabela 1 são apresentadas as estatísticas descritivas dos indicadores econômico-financeiros e socioambientais das empresas distribuidoras de energia elétrica, filiadas ao Operador Nacional do Sistema Elétrico (ONS).

Tabela 1 - Estatística descritiva das variáveis

\begin{tabular}{c|c|c|c|c|c|c|c}
\hline \multirow{2}{*}{ Empresas } & \multicolumn{3}{|c|}{ Indicadores Econômico-financeiros } & \multicolumn{2}{c}{ Indicadores de Socioambientais } \\
\cline { 2 - 8 } & REN (\%) & LL & GC & RL & ISI & ISE & IA \\
\hline Máximo & 79,29 & 1.575 .942 & 2.847 .853 & 9.835 .578 & 906.996 & 5.111 .764 & 140.852 \\
\hline Mínimo & 0,00 & -391.162 & -47.823 & 147.300 & 6.547 & 0,00 & 0,00 \\
\hline Média & 19,95 & 243.317 & 467.706 & 2.376 .447 & 134.199 & 1.1192 .859 & 22.593 \\
\hline Mediana & 17,60 & 122.900 & 283.153 & 1.912 .100 & 59.111 & 818.900 & 11.769 \\
\hline Desvio-Padrão & 18,91 & 411.845 & 587.479 & 2.333 .178 & 192.346 & 1.275 .724 & 31.276 \\
\hline
\end{tabular}

Fonte: Dados da pesquisa.

Conforme apresentado na Tabela 1, pode-se perceber das variáveis socioambientais o indicador que apresentou maior desvio-padrão, isto é, uma maior discrepância entre o valor mínimo e o valor máximo dos dados, foi o ISE. Essa observação demonstra que as empresas possuem uma grande diferença, quanto a interação da entidade com o ambiente externo. Em contrapartida, o indicador socioambiental que apresentou menor desvio-padrão para as empresas distribuidoras de energia elétrica foi o que mede os indicadores ambientais (IA), que é encontrado pela interação da entidade com o meio ambiente, demonstrando que não existe uma grande variabilidade de investimento no meio ambiente entre as entidades.

Observam-se nos dados apresentados na Tabela 1 que a maior heterogeneidade entre os indicadores econômico-financeiros das empresas refere-se à Receita Líquida (RL), ou seja, 
existe uma grande diferença entre as receitas líquidas das empresas, devendo levar em consideração que o valor da tarifa nas empresas do setor de energia ser regulado pela Agência Nacional de Energia Elétrica (ANEEL). Outrossim, existe uma proximidade da rentabilidade obtida pelas empresas distribuidoras de energia elétrica, ou seja, o lucro líquido em relação ao patrimônio líquido das empresas foram próximos.

Para uma melhor aplicação do método multicritério para tomada de decisão VIKOR, procedeuse a normalização dos dados coletados, tanto os dados de liquidez quanto os dados de rentabilidade. Para tanto, utilizou-se a seguinte métrica:

$$
x_{i_{N}}^{k}=\frac{x_{i}^{k}}{\sqrt{\left(x_{i}^{l}\right)^{2}+\left(x_{i}^{2}\right)^{2}+\ldots+\left(x_{i}^{k}\right)^{2}}}
$$

$\mathrm{Na}$ Tabela 2 são apresentadas as variáveis econômico-financeiras e socioambientais normalizadas, com suas estatísticas descritivas.

Tabela 2 - Estatística descritiva das variáveis normalizadas

\begin{tabular}{c|c|c|c|c|c|c|c}
\hline \multirow{2}{*}{ Empresas } & \multicolumn{3}{|c|}{ Indicadores Econômico-financeiros } & \multicolumn{2}{c}{ Indicadores de Socioambientais } \\
\cline { 2 - 8 } & REN (\%) & LL & GC & RL & ISI & ISE & IA \\
\hline Máximo & 13,14 & 13,24 & 14,05 & 13,20 & 14,02 & 13,07 & 13,78 \\
\hline Mínimo & 8,95 & 8,47 & 9,12 & 9,04 & 9,34 & 9,06 & 9,28 \\
\hline Média & 10,00 & 10,00 & 10,00 & 10,00 & 10,00 & 10,00 & 10,00 \\
\hline Mediana & 9,88 & 9,71 & 9,69 & 9,80 & 9,61 & 9,71 & 9,65 \\
\hline Desvio-Padrão & 1,00 & 1,00 & 1,00 & 1,00 & 1,00 & 1,00 & 1,00 \\
\hline
\end{tabular}

Fonte: Dados da pesquisa.

$\mathrm{Na}$ sequência foram elaborados, por meio do método VIKOR, os rankings das variáveis econômico-financeiras e socioambientais das empresas. A Tabela 3 apresenta o ranking geral de indicadores econômico-financeiros das empresas distribuidoras de energia elétrica associadas ao Operador Nacional do Sistema Elétrico (ONS).

Tabela 3 - Ranking geral dos indicadores econômico-financeiros

\begin{tabular}{|c|c|c|c|c|c|c|c|c|c|}
\hline \multirow{2}{*}{$\begin{array}{c}\text { Posiçã } \\
\text { o }\end{array}$} & \multicolumn{4}{|c|}{ Econômico-financeiros } & \multirow{2}{*}{$\begin{array}{c}\text { Posiçã } \\
\text { o }\end{array}$} & \multicolumn{4}{|c|}{ Econômico-financeiros } \\
\hline & Empresas & $\mathbf{S}$ & $\mathbf{R}$ & $\mathbf{Q}$ & & Empresas & $\mathbf{S}$ & $\mathbf{R}$ & $\mathbf{Q}$ \\
\hline $1^{\mathrm{o}}$ & $\begin{array}{c}\text { ELETROPAUL } \\
\mathrm{O}\end{array}$ & $\begin{array}{c}0,50 \\
7\end{array}$ & $\begin{array}{c}0,50 \\
6\end{array}$ & - & $19^{\circ}$ & $\begin{array}{l}\text { ENERGISA } \\
\text { PARAÍBA }\end{array}$ & $\begin{array}{c}3,28 \\
4\end{array}$ & $\begin{array}{c}0,91 \\
6\end{array}$ & $\begin{array}{c}0,83 \\
9\end{array}$ \\
\hline $2^{\circ}$ & CPFL & $\begin{array}{c}1,67 \\
0\end{array}$ & $\begin{array}{c}0,60 \\
4\end{array}$ & $\begin{array}{c}0,27 \\
7\end{array}$ & $20^{\circ}$ & ELETRONORTE & $\begin{array}{c}2,87 \\
8\end{array}$ & $\begin{array}{c}0,99 \\
3\end{array}$ & $\begin{array}{c}0,85 \\
4\end{array}$ \\
\hline $3^{\circ}$ & CEMIG & $\begin{array}{c}1,61 \\
6\end{array}$ & $\begin{array}{c}0,61 \\
8\end{array}$ & $\begin{array}{c}0,28 \\
3\end{array}$ & $21^{\circ}$ & ENERGISA MG & $\begin{array}{c}3,05 \\
2\end{array}$ & $\begin{array}{c}0,97 \\
1\end{array}$ & $\begin{array}{c}0,85 \\
9\end{array}$ \\
\hline $4^{\circ}$ & COELBA & $\begin{array}{c}2,05 \\
0\end{array}$ & $\begin{array}{c}0,58 \\
8\end{array}$ & $\begin{array}{c}0,31 \\
8\end{array}$ & $22^{\circ}$ & $\begin{array}{l}\text { ENERGISA } \\
\text { SERGIPE }\end{array}$ & $\begin{array}{c}3,46 \\
1\end{array}$ & $\begin{array}{c}0,94 \\
8\end{array}$ & $\begin{array}{c}0,89 \\
8\end{array}$ \\
\hline $5^{\circ}$ & ELEKTRO & $\begin{array}{c}2,40 \\
5\end{array}$ & $\begin{array}{c}0,66 \\
1\end{array}$ & $\begin{array}{c}0,44 \\
6\end{array}$ & $23^{\circ}$ & CELTINS & $\begin{array}{c}3,57 \\
0\end{array}$ & $\begin{array}{c}0,93 \\
8\end{array}$ & $\begin{array}{c}0,90 \\
5\end{array}$ \\
\hline $6^{\circ}$ & $\begin{array}{c}\text { CPFL } \\
\text { PIRATININGA }\end{array}$ & $\begin{array}{c}2,18 \\
5\end{array}$ & $\begin{array}{c}0,78 \\
6\end{array}$ & $\begin{array}{c}0,54 \\
0\end{array}$ & $24^{\circ}$ & CLFSC & $\begin{array}{c}3,40 \\
2\end{array}$ & $\begin{array}{c}0,99 \\
1\end{array}$ & $\begin{array}{c}0,93 \\
2\end{array}$ \\
\hline $7^{\circ}$ & COPEL & $\begin{array}{c}2,53 \\
3\end{array}$ & $\begin{array}{c}0,79 \\
6\end{array}$ & $\begin{array}{c}0,60 \\
2\end{array}$ & $25^{\circ}$ & LIGHT & $\begin{array}{c}3,46 \\
7\end{array}$ & $\begin{array}{c}0,98 \\
1\end{array}$ & $\begin{array}{c}0,93 \\
2\end{array}$ \\
\hline $8^{\circ}$ & CELESC & $\begin{array}{c}2,76 \\
4\end{array}$ & $\begin{array}{c}0,79 \\
6\end{array}$ & $\begin{array}{c}0,63 \\
8\end{array}$ & $26^{\circ}$ & $\begin{array}{c}\text { ENERGISA } \\
\text { BORBOREMA }\end{array}$ & $\begin{array}{c}3,51 \\
5\end{array}$ & $\begin{array}{c}1,00 \\
0\end{array}$ & $\begin{array}{c}0,95 \\
9\end{array}$ \\
\hline $9^{\circ}$ & CELPE & $\begin{array}{c}2,93 \\
7\end{array}$ & $\begin{array}{c}0,78 \\
7\end{array}$ & $\begin{array}{c}0,65 \\
6\end{array}$ & $27^{\circ}$ & EEVP & $\begin{array}{c}3,64 \\
9\end{array}$ & $\begin{array}{c}0,99 \\
0\end{array}$ & $\begin{array}{c}0,96 \\
9\end{array}$ \\
\hline
\end{tabular}

R. Cont. Ufba, Salvador-Ba, v. 7, n. 3, p. 59 - 73, dezembro-março 2014 


\begin{tabular}{c|c|c|c|c|c|c|c|c|c}
\hline $10^{\circ}$ & SUL & $\begin{array}{c}2,92 \\
0\end{array}$ & $\begin{array}{c}0,81 \\
4\end{array}$ & $\begin{array}{c}0,68 \\
0\end{array}$ & $28^{\circ}$ & EEB & $\begin{array}{c}3,66 \\
8\end{array}$ & $\begin{array}{c}0,99 \\
0\end{array}$ & $\begin{array}{c}0,97 \\
2\end{array}$ \\
\hline $11^{\circ}$ & EBE & $\begin{array}{c}2,91 \\
6\end{array}$ & $\begin{array}{c}0,81 \\
7\end{array}$ & $\begin{array}{c}0,68 \\
3\end{array}$ & $29^{\circ}$ & CEB & $\begin{array}{c}3,62 \\
8\end{array}$ & $\begin{array}{c}1,00 \\
0\end{array}$ & $\begin{array}{c}0,97 \\
6\end{array}$ \\
\hline $12^{\circ}$ & RGE & $\begin{array}{c}3,03 \\
3\end{array}$ & $\begin{array}{c}0,80 \\
3\end{array}$ & $\begin{array}{c}0,68 \\
6\end{array}$ & $30^{\circ}$ & CELPA & $\begin{array}{c}3,65 \\
0\end{array}$ & $\begin{array}{c}1,00 \\
0\end{array}$ & $\begin{array}{c}0,97 \\
9\end{array}$ \\
\hline $13^{\circ}$ & CEMAR & $\begin{array}{c}2,98 \\
6\end{array}$ & $\begin{array}{c}0,81 \\
8\end{array}$ & $\begin{array}{c}0,69 \\
4\end{array}$ & $31^{\circ}$ & CEPISA & $\begin{array}{c}3,69 \\
6\end{array}$ & $\begin{array}{c}1,00 \\
0\end{array}$ & $\begin{array}{c}0,98 \\
6\end{array}$ \\
\hline $14^{\circ}$ & CEMAT & $\begin{array}{c}3,18 \\
7\end{array}$ & $\begin{array}{c}0,85 \\
5\end{array}$ & $\begin{array}{c}0,76 \\
2\end{array}$ & $32^{\circ}$ & CEEE & $\begin{array}{c}3,70 \\
4\end{array}$ & $\begin{array}{c}1,00 \\
0\end{array}$ & $\begin{array}{c}0,98 \\
7\end{array}$ \\
\hline $15^{\circ}$ & CHESF & $\begin{array}{c}2,43 \\
3\end{array}$ & $\begin{array}{c}0,98 \\
2\end{array}$ & $\begin{array}{c}0,77 \\
6\end{array}$ & $33^{\circ}$ & CEAL & $\begin{array}{c}3,76 \\
2\end{array}$ & $\begin{array}{c}1,00 \\
0\end{array}$ & $\begin{array}{c}0,99 \\
6\end{array}$ \\
\hline $16^{\circ}$ & COSERN & $\begin{array}{c}3,07 \\
1\end{array}$ & $\begin{array}{c}0,89 \\
7\end{array}$ & $\begin{array}{c}0,78 \\
6\end{array}$ & $34^{\circ}$ & CERON & $\begin{array}{c}3,76 \\
2\end{array}$ & $\begin{array}{c}1,00 \\
0\end{array}$ & $\begin{array}{c}0,99 \\
6\end{array}$ \\
\hline $17^{\circ}$ & ENERSUL & $\begin{array}{c}3,21 \\
7\end{array}$ & $\begin{array}{c}0,87 \\
7\end{array}$ & $\begin{array}{c}0,78 \\
9\end{array}$ & \multirow{2}{*}{$35^{\circ}$} & CAIUÁ & $\begin{array}{c}3,78 \\
6\end{array}$ & $\begin{array}{c}1,00 \\
0\end{array}$ & $\begin{array}{c}1,00 \\
0\end{array}$ \\
\hline $18^{\circ}$ & ESCELSA & $\begin{array}{c}3,31 \\
1\end{array}$ & $\begin{array}{c}0,88 \\
9\end{array}$ & $\begin{array}{c}0,81 \\
5\end{array}$ & & & & & 0
\end{tabular}

Fonte: Dados da pesquisa.

A Tabela 4 apresenta o ranking geral de indicadores socioambientais das empresas distribuidoras de energia elétrica associadas ao Operador Nacional do Sistema Elétrico (ONS).

Tabela 4 - Ranking geral dos indicadores socioambientais

\begin{tabular}{|c|c|c|c|c|c|c|c|c|c|}
\hline \multirow{2}{*}{$\begin{array}{l}\text { Posiçã } \\
\text { o }\end{array}$} & \multicolumn{4}{|c|}{ Socioambientais } & \multirow{2}{*}{$\begin{array}{l}\text { Posiçã } \\
\text { o }\end{array}$} & \multicolumn{4}{|c|}{ Socioambientais } \\
\hline & Empresas & $\mathbf{S}$ & $\mathbf{R}$ & $\mathbf{Q}$ & & Empresas & $\mathbf{S}$ & $\mathbf{R}$ & $\mathbf{Q}$ \\
\hline $1^{\circ}$ & COPEL & $\begin{array}{c}0,27 \\
6\end{array}$ & $\begin{array}{c}0,27 \\
6\end{array}$ & - & $19^{\circ}$ & ENERSUL & $\begin{array}{c}2,77 \\
3\end{array}$ & $\begin{array}{c}0,95 \\
3\end{array}$ & $\begin{array}{c}0,93 \\
0\end{array}$ \\
\hline $2^{\circ}$ & $\begin{array}{c}\text { ELETROPAUL } \\
\mathrm{O} \\
\end{array}$ & $\begin{array}{c}1,24 \\
7 \\
\end{array}$ & $\begin{array}{c}0,57 \\
7\end{array}$ & $\begin{array}{c}0,38 \\
8 \\
\end{array}$ & $20^{\circ}$ & CEMAR & $\begin{array}{c}2,79 \\
1\end{array}$ & $\begin{array}{c}0,95 \\
7 \\
\end{array}$ & $\begin{array}{c}0,93 \\
6 \\
\end{array}$ \\
\hline $3^{\circ}$ & CELESC & $\begin{array}{c}1,61 \\
4\end{array}$ & $\begin{array}{c}0,72 \\
2\end{array}$ & $\begin{array}{c}0,55 \\
6\end{array}$ & $21^{\circ}$ & COSERN & $\begin{array}{c}2,78 \\
6\end{array}$ & $\begin{array}{c}0,96 \\
6\end{array}$ & $\begin{array}{c}0,94 \\
1\end{array}$ \\
\hline $4^{\circ}$ & CEMIG & $\begin{array}{c}1,26 \\
5\end{array}$ & $\begin{array}{c}0,82 \\
7\end{array}$ & $\begin{array}{c}0,56 \\
4 \\
\end{array}$ & $22^{\circ}$ & $\begin{array}{l}\text { ENERGISA } \\
\text { PARAIIBA }\end{array}$ & $\begin{array}{c}2,84 \\
9 \\
\end{array}$ & $\begin{array}{c}0,97 \\
1\end{array}$ & $\begin{array}{c}0,95 \\
6 \\
\end{array}$ \\
\hline $5^{\circ}$ & CPFL & $\begin{array}{c}2,03 \\
0\end{array}$ & $\begin{array}{c}0,84 \\
4\end{array}$ & $\begin{array}{c}0,71 \\
7\end{array}$ & $23^{\circ}$ & CEMAT & $\begin{array}{c}2,76 \\
9\end{array}$ & $\begin{array}{c}0,99 \\
2\end{array}$ & $\begin{array}{c}0,95 \\
6\end{array}$ \\
\hline $6^{\circ}$ & CHESF & $\begin{array}{c}2,09 \\
0\end{array}$ & $\begin{array}{c}0,83 \\
0\end{array}$ & $\begin{array}{c}0,71 \\
8\end{array}$ & $24^{\circ}$ & $\begin{array}{l}\text { ENERGISA } \\
\text { SERGIPE }\end{array}$ & $\begin{array}{c}2,84 \\
6\end{array}$ & $\begin{array}{c}0,97 \\
5\end{array}$ & $\begin{array}{c}0,95 \\
8\end{array}$ \\
\hline $7^{\circ}$ & COELBA & $\begin{array}{c}1,98 \\
4\end{array}$ & $\begin{array}{c}0,87 \\
3\end{array}$ & $\begin{array}{c}0,72 \\
9\end{array}$ & $25^{\circ}$ & CEB & $\begin{array}{c}2,81 \\
4\end{array}$ & $\begin{array}{c}0,99 \\
6\end{array}$ & $\begin{array}{c}0,96 \\
7\end{array}$ \\
\hline $8^{\circ}$ & ELEKTRO & $\begin{array}{c}2,19 \\
9\end{array}$ & $\begin{array}{c}0,84 \\
0\end{array}$ & $\begin{array}{c}0,74 \\
5\end{array}$ & $26^{\circ}$ & CELTINS & $\begin{array}{c}2,87 \\
7\end{array}$ & $\begin{array}{c}0,98 \\
2\end{array}$ & $\begin{array}{c}0,96 \\
9\end{array}$ \\
\hline $9^{\circ}$ & LIGHT & $\begin{array}{c}2,01 \\
9 \\
\end{array}$ & $\begin{array}{c}0,89 \\
8\end{array}$ & $\begin{array}{c}0,75 \\
2 \\
\end{array}$ & $27^{\circ}$ & ENERGISA MG & $\begin{array}{c}2,87 \\
7 \\
\end{array}$ & $\begin{array}{c}0,99 \\
4 \\
\end{array}$ & $\begin{array}{c}0,97 \\
7 \\
\end{array}$ \\
\hline $10^{\circ}$ & $\begin{array}{c}\text { ELETRONOR } \\
\text { TE }\end{array}$ & $\begin{array}{c}2,15 \\
8\end{array}$ & $\begin{array}{c}0,90 \\
0\end{array}$ & $\begin{array}{c}0,77 \\
9\end{array}$ & $28^{\circ}$ & CERON & $\begin{array}{c}2,89 \\
2\end{array}$ & $\begin{array}{c}1,00 \\
0\end{array}$ & $\begin{array}{c}0,98 \\
4\end{array}$ \\
\hline $11^{\circ}$ & CELPE & $\begin{array}{c}2,13 \\
5\end{array}$ & $\begin{array}{c}0,91 \\
7\end{array}$ & $\begin{array}{c}0,78 \\
6 \\
\end{array}$ & $29^{\circ}$ & CEAL & $\begin{array}{c}2,90 \\
4\end{array}$ & $\begin{array}{c}1,00 \\
0\end{array}$ & $\begin{array}{c}0,98 \\
6 \\
\end{array}$ \\
\hline $12^{\circ}$ & CEEE & $\begin{array}{c}2,60 \\
8\end{array}$ & $\begin{array}{c}0,92 \\
6\end{array}$ & $\begin{array}{c}0,88 \\
1\end{array}$ & $30^{\circ}$ & CEPISA & $\begin{array}{c}2,92 \\
5\end{array}$ & $\begin{array}{c}1,00 \\
0\end{array}$ & $\begin{array}{c}0,99 \\
0\end{array}$ \\
\hline $13^{\circ}$ & SUL & $\begin{array}{c}2,61 \\
4\end{array}$ & $\begin{array}{c}0,93 \\
1\end{array}$ & $\begin{array}{c}0,88 \\
5\end{array}$ & $31^{\circ}$ & CAIUÁ & $\begin{array}{c}2,95 \\
8\end{array}$ & $\begin{array}{c}0,99 \\
4\end{array}$ & $\begin{array}{c}0,99 \\
2\end{array}$ \\
\hline $14^{\circ}$ & $\begin{array}{c}\text { CPFL } \\
\text { PIRATININGA }\end{array}$ & $\begin{array}{c}2,57 \\
8\end{array}$ & $\begin{array}{c}0,94 \\
7\end{array}$ & $\begin{array}{c}0,88 \\
9\end{array}$ & $32^{\circ}$ & CLFSC & $\begin{array}{c}2,95 \\
9\end{array}$ & $\begin{array}{c}0,99 \\
9\end{array}$ & $\begin{array}{c}0,99 \\
6\end{array}$ \\
\hline $15^{\circ}$ & CELPA & $\begin{array}{c}2,63 \\
1\end{array}$ & $\begin{array}{c}0,94 \\
4\end{array}$ & $\begin{array}{c}0,89 \\
7\end{array}$ & $33^{\circ}$ & EEVP & $\begin{array}{c}2,97 \\
4\end{array}$ & $\begin{array}{c}0,99 \\
8\end{array}$ & $\begin{array}{c}0,99 \\
8\end{array}$ \\
\hline
\end{tabular}




\begin{tabular}{|c|c|c|c|c|c|c|c|c|c|}
\hline $16^{\circ}$ & EBE & $\begin{array}{c}2,56 \\
8\end{array}$ & $\begin{array}{c}0,96 \\
5\end{array}$ & $\begin{array}{c}0,90 \\
0\end{array}$ & $34^{\circ}$ & EEB & $\begin{array}{c}2,96 \\
7\end{array}$ & $\begin{array}{c}1,00 \\
0\end{array}$ & $\begin{array}{c}0,99 \\
8\end{array}$ \\
\hline $17^{\circ}$ & RGE & $\begin{array}{c}2,62 \\
9\end{array}$ & $\begin{array}{c}0,95 \\
7\end{array}$ & $\begin{array}{c}0,90 \\
6\end{array}$ & \multirow{2}{*}{$35^{\circ}$} & \multirow{2}{*}{$\begin{array}{l}\text { ENERGISA } \\
\text { BORBOREMA }\end{array}$} & \multirow{2}{*}{$\begin{array}{c}2,97 \\
8\end{array}$} & \multirow{2}{*}{$\begin{array}{c}1,00 \\
0\end{array}$} & \multirow{2}{*}{$\begin{array}{c}1,00 \\
0\end{array}$} \\
\hline $18^{\circ}$ & ESCELSA & $\begin{array}{c}2,67 \\
4\end{array}$ & $\begin{array}{c}0,94 \\
9\end{array}$ & $\begin{array}{c}0,90 \\
8\end{array}$ & & & & & \\
\hline
\end{tabular}

Fonte: Dados da pesquisa.

Segundo o exposto na Tabela 3 e 4, a empresa Eletropaulo foi a que apresentou um melhor desempenho econômico-financeiro dentre as empresas pesquisadas, no ranking socioambiental passa a ser a segunda colocada, ou seja, foi a organização que mais investiu no socioambiental. Estes achados vão ao encontro dos estudos Castro Júnior, Abreu e Soares (2005), Arrantes (2006), Ceretta et al. (2009), Machado e Machado (2011), Souza, Parisotto e Marcondes (2011) e Orelano e Quiota (2011). Conforme os estudos, o crescimento dos indicadores socioambientais foi acompanhado pelas variáveis econômico-financeiras, assim o resultado apresentado pela Eletropaulo corrobora com a literatura.

Ainda de acordo com a Tabela 3 e 4, a Energisa Borborema foi a última colocada no ranking socioambiental e a $26^{\circ}$ colocada no ranking econômico-financeira, caracterizando-se, portanto como uma das piores empresas analisadas. Conforme os resultados apresentados pela literatura, empresas com um maior investimento socioambiental apresentam um melhor desempenho econômico-financeiro e vice e versa. Dessa forma, o resultado apresentado pela Energisa Borborema vai ao encontro dos estudos anteriores, visto que o investimento socioambiental é acompanhado pelo desempenho econômico-financeiro, sua baixa posição em um ranking ocorreu também no outro.

De forma geral, observou-se que as empresas com melhores desempenhos econômicofinanceiros, também são nos aspectos de responsabilidade socioambiental e vice-versa. Contudo é necessário verificar se existe uma relação através da aplicação de uma técnica estatística. Desta forma, a Tabela 5 apresenta a aplicação da correlação de Kendall.

Tabela 5 - Coeficiente de correlação de Kendall

\begin{tabular}{c|c|c}
\hline \multicolumn{2}{|c|}{} & Socioambientais \\
\hline \multirow{2}{*}{ Econômico-financeiros } & Coeficiente de correlação & 0,583 \\
\cline { 2 - 3 } & Significância & 0,000 \\
\hline
\end{tabular}

Fonte: Dados da pesquisa.

Conforme evidenciado na Tabela 5, se constatou uma correlação positivamente significante ao nível de $1 \%$ entre os rankings socioambientais e econômico-financeiros pelo método VIKOR. Assim, verifica-se que quanto maior for os desempenho econômico-financeiro, maior será o investimento socioambiental, das empresas distribuidoras de energia elétrica, filiadas ao Operador Nacional do Sistema Elétrico (ONS). Essa pesquisa corrobora com os estudos de Castro Júnior, Abreu e Soares (2005), Arrantes (2006), Ceretta et al. (2009), Machado e Machado (2011), Souza, Parisotto e Marcondes (2011) e Orelano e Quiota (2011).

Dessa forma, os achados apresentados pelas empresas distribuidoras de energia elétrica, filiadas ao Operador Nacional do Sistema Elétrico (ONS) são os mesmos encontrados por outros estudos que analisaram as empresas que pertencem ao setor de energia elétrica (SOUZA; PARISOTTO; MARCONDES, 2011; HOLANDA et al., 2011) e por estudos que analisaram organizações de diversos setores no âmbito nacional (CASTRO JÚNIOR; ABREU; SOARES, 2005; CERETTA et al., 2009; MACHADO; MACHADO, 2011; ORELLANO; QUIOTA. 2011). Assim, o investimento realizado pelas empresas distribuidoras de energia elétrica está positivamente correlacionado com seu desempenho empresarial. Por fim, os resultados 
apresentados na pesquisa, contradizem os estudos de Borba (2005), Tupy (2008) e Holanda et al. (2001), pois os mesmos não encontraram correlação significativa positiva entre o desempenho econômico-financeiro e o investimento socioambiental.

\section{Considerações Finais}

Este estudo objetivou analisar a relação dos rankings formados pelos indicadores econômicofinanceiros e socioambientais, das empresas distribuidoras de energia elétrica, filiadas ao Operador Nacional do Sistema Elétrico (ONS) no ano de 2011, por meio do método multicritério para tomada de decisão VIKOR. Para atingir o objetivo inicialmente utilizou-se estatística descritiva, com o intuito de caracterizar a amostra da pesquisa. Em seguida efetuouse a normalização dos dados. Na sequência foi realizado os rankings socioambientais e econômico-financeiros. Por fim, utilizou-se o coeficiente de correlação de Kendall para determinar o grau de relacionamento entre os rankings elaborados.

Para os rankings criado pelo método VIKOR, destaca-se a empresa Eletropaulo foi a que apresentou um melhor desempenho econômico-financeiro dentre as empresas pesquisadas, no ranking socioambiental passa a ser a segunda colocada, ou seja, foi a organização que mais investiu no socioambiental. Já a Energisa Borborema apresentou um dos menores desempenho econômico-financeiro, além disso foi a que menos investiu no socioambiental.

As posições da Eletropaulo e da Energisa Borborema nos ranking, corroboram com a ideia de que empresas com alto desempenho empresarial, também possuem alto investimento socioambiental e vice e versa. Contudo, foi necessário aplicar uma técnica estatística para verificar a relação entre as variáveis, através dos rankings.

Os resultados encontrados pela correlação de Kendall apontaram uma relação positivamente significativa ao nível de $1 \%$ entre os rankings, corroborando com os estudos de Castro Júnior, Abreu e Soares (2005), Arrantes (2006), CERETTA et al. (2009), Machado e Machado (2011), Souza, Parisotto e Marcondes (2011) e Orelano e Quiota (2011). Desta forma, considera-se que as empresas distribuidoras de energia elétrica, filiadas ao Operador Nacional do Sistema Elétrico (ONS), com alto desempenho econômico-financeiro, são mais preocupadas com o desenvolvimento socioambiental,

As limitações deste estudo consistem na impossibilidade da generalização dos resultados, visto que a amostra é composta apenas por empresas distribuidoras de energia elétrica, filiadas ao Operador Nacional do Sistema Elétrico (ONS), resultando a uma amostra pequena. Para trabalhos futuros, sugere: aumentar tamanho da amostra, ou alterar o grupo de empresas pesquisadas; ampliar o período de análise; alterar o conjunto de indicadores utilizados; e realizar uma pesquisa mais detalhada com um número reduzido de empresas, alterando o caráter da pesquisa para qualitativo. Assim, novas pesquisas poderão utilizar este estudo para fins de comparabilidade dos resultados.

\section{REFERÊNCIAS}

ARANTES, E. Investimento em responsabilidade social e sua relação com o desempenho das empresas. Conhecimento Interativo, v. 2, n. 1, p. 03-09, jan./jun. 2006.

BORBA, Paulo da Rocha Ferreira. Relação entre desempenho social corporativo e desempenho financeiro de empresas no Brasil. 2005. Dissertação (Mestrado em 
Administração) - Faculdade de Economia, Administração e Contabilidade, Universidade de São Paulo, São Paulo, 2005.

CALIXTO, Laura. Responsabilidade socioambiental: pública ou privada? Revista Contabilidade Vista e Revista, v. 19, n. 3, p. 123-147, jul./set. 2008.

CASTRO JÚNIOR, Orlando Vieira; ABREU, Mônica Cavalcanti Sá de; SOARES, Francisco de Assis. Efeito da conduta ambiental sobre a performance econômica dentro do modelo ECP-triplo: evidências da indústria têxtil brasileira. In: ENCONTRO DA ASSOCIAÇÃO NACIONAL DE PÓS-GRADUAÇÃO E PESQUISA EM ADMINISTRAÇÃO. Anais... Florianópolis: ANPAD, 2005.

CERETTA, Paulo Sérgio; BARBA, Fernanda Galvão de; CASARIN, Fernando; KRUEL, Maximiliano; MILANI, Bruno. Desempenho financeiro e a questão dos investimentos sócioambientais. Revista de Gestão Social e Ambienta, v. 3, n. 3, p. 72-84, set./dez. 2009.

DONALDSON, Thomas; PRESTON, Lee E. The stakeholder theory of the corporation: concepts, evidence and implications. Academy of Management Review, v. 20, n. 1, p. 6591, jan. 1995.

ELKINGTON, John. Cannibals with forks: the triple bottom line of 21st century busines. Capstone Publishing: Oxford, 1998.

FERREIRA, Roberto do Nascimento. Responsabilidade social, governança corporativa e valor das empresas. Revista de Administração da UFLA, v. 6, n. 1, p. 132-143, jan./jun. 2004.

FREEMAN, R. Edward. REED, David L. Stockholders and stakeholders: a new perspective on corporate governance. Califórnia Management Review, v. 25, n. 3, p. 88-106, 1983.

FREEMAN, R. Edward. Strategic management: a stakeholder approach. Boston: Pitman, 1984.

FREEMAN, R. Edward; MCVEA, John. A stakeholder approach to strategic management. Darden Business School Working, v. 1/2, n. 1, mar. 2001.

FRIEDMAN, Milton. The social responsibility of business is to increase its profits. New York Times Magazine, v. 33, p. 122-126, sep. 1970.

HOLANDA, Allan Pinheiro; ALMADA, Sylene Ruiz de; DE LUCA, Márcia Martins; GALLON, Alessandra Vasconcelos. O desempenho socioambiental nas empresas do setor elétrico brasileiro: uma questão relevante para o desempenho financeiro? Revista de Gestão Social e Ambiental, v. 5, n. 3, p. 53-72, set./dez. 2011.

IBASE. Balanço social. Disponível em: <http://www.balancosocial.org.br>. Acesso em: 01 abril 2013. 
INSTITUTO ETHOS DE EMPRESAS E RESPONSABILIDADE SOCIAL. Critérios essenciais de responsabilidade social empresarial e seus mecanismos de indução no Brasil. São Paulo: Ethos, 2006.

KENDALL, Maurice G. Rank correlation methods. London: Griffin, 1970.

LEVITT, Theodore. The dangers of social responsibility. Harvard Business Review, v. 36, n. 5, sep. 1958.

MACHADO, Márcio André Veras; MACHADO, Márcia Reis. Responsabilidade social impacta o desempenho financeiro das empresas? Advances in Scientific and Applied Accounting, v. 4, n. 1, p. 2-23, 2011.

MARCONI, Marina de Andrade; LAKATOS, Eva Maria. Fundamentos de metodologia científica. 7. ed. São Paulo: Atlas, 2010.

MITCHELL, Ronald K.; AGLE, Bradley R.; WOOD, Donna J. Toward a theory of stakeholder identification and salience: defining the principle of who and what really counts. The Academy of Management Review, v. 22, n. 4, p. 853-886, oct. 1997.

OPRICOVIC, Serafim; Tzeng, Gwo-Hshiung. Compromise solution by MCDM methods: A comparative analysis of VIKOR and TOPSIS. European Journal of Operational Research, v. 156, n. 2, p. 445-455, jul. 2004.

OPRICOVIC, Serafim; Tzeng, Gwo-Hshiung. Extended VIKOR method in comparison with outranking methods. European Journal of Operational Research, v. 178, n. 2, p. 514-529, apr. 2007.

ORELLANO, Verônica Ines Fernandez; QUIOTA, Silvia. Análise do retorno dos investimentos socioambientais das empresas brasileiras. Revista de Administração de Empresas, v. 51, n. 5, p. 471-484, set./out. 2011.

REZENDE, Idália Antunes Cangussú; NUNES, Julyana Goldner; PORTELA, Simone Salles. Um estudo sobre o desempenho financeiro do índice Bovespa de sustentabilidade empresarial. Revista de Educação e Pesquisa em Contabilidade, v. 2, n. 1, p. 71-93, jan./abr. 2008.

RICHARDSON, Roberto Jarry; Pesquisa social: métodos e técnicas. 3. ed. São Paulo: Atlas, 1999.

SOUZA, Maria Tereza Saraiva de; PARISOTTO, Iara Regina dos Santos; MARCONDES, Nilton Rogério. Um estudo do impacto financeiro do balanço social em empresas do setor de eletricidade. Perspectiva Contemporânea, v. 6, n. 1, p. 105-130, jan./jun. 2011.

TUPY, Oscar. Investimentos em meio ambiente, responsabilidade social e desempenho econômico-financeiro de empresas no Brasil. Revista de Estudos Politécnicos, v. 6, n. 10, p. 73-86, 2008. 
TZENG, Gwo-Hshiung; LIN, Cheng-Wei; OPRICOVIC, Serafim. Multi-criteria analysis of alternative-fuel buses for public transportation. Energy Policy, v. 33, n. 11, p. 1373-1383, jul. 2005 .

VERGARA, Sylvia Constant. Métodos de pesquisa em administração. 2. ed. São Paulo: Atlas, 2006. 